\title{
Application of Component Criticality Importance Measures in Design Scheme of Power Plants
}

\author{
Smajo Bisanovic*, Mersiha Samardzic**, Damir Aganovic* \\ * Public Enterprise Elektroprivreda of Bosnia and Herzegovina d.d. - Sarajevo, Bosnia and Herzegovina \\ ** Faculty of Electrical Engineering, University of Sarajevo, Bosnia and Herzegovina
}

\begin{tabular}{l} 
Article Info \\
\hline Article history: \\
Received Sep 22, 2015 \\
Revised Nov 11, 2015 \\
Accepted Nov 28, 2015 \\
\hline Keyword: \\
Criticality importance measures \\
Design scheme \\
Discrete event \\
Reliability \\
Thermal power plant
\end{tabular}

\begin{abstract}
This paper presents application of component criticality importance measures in phase of preparation and design of power plants. These measures provide a numerical rank to determine which components are more important for power plant reliability improvement or more critical for power plant failure. Identifying critical components for power plant reliability provides an important input for decision-making and guidance throughout the development project. The study on several schematic design options of conventional thermal power plant show that the importance measures can be used as an effective tool to assess component criticality in the project phase of new production capacities.
\end{abstract}

Copyright (c) 2016 Institute of Advanced Engineering and Science. All rights reserved.

\section{Corresponding Author:}

Smajo Bisanovic,

Public Enterprise Elektroprivreda of Bosnia and Herzegovina d.d. - Sarajevo,

Vilsonovo setaliste 15,

71000 Sarajevo, Bosnia and Herzegovina.

Email: s.bisanovic@elektroprivreda.ba

\section{INTRODUCTION}

Thermal power plant design is characterized by major complexity of equipment and technological schemes that requires an increased attention in their reliability. Therefore, a power plant design must be able to quantify reliable and cost-effective choice of components with respect to the impact they have on plant reliability. Design could be optimized by risk, ranking the importance of components. When components with significant risk are selected this way, the risk frequency can be improved by decreasing the unavailability of the selected components, modification/replacement with higher reliability components, improving the defense in root of failure occurrence component or decreasing the contribution frequencies of initial event [1].

Component importance measures are commonly used in risk assessments, particularly probabilistic risk assessments of nuclear power plants [2, 3]. In power industry, component importance measures are applied in different configurations of electrical networks design [4-6]. In these applications, the component importance measures are called risk importance measures and are used to identify components that should be improved in order to reduce the risk and identify components for risk-based service inspection and testing.

Component importance measures are applied in different phases of the plant's life cycle. In the design phase, the importance measure may be used to identify weak points and components that should be improved to increase the plant reliability. Reliability of a component may be improved by using a higher quality component, introducing redundant components, reducing the operational and environmental loads on the component or by improving its maintainability. The optimal improvements are a complex problem and out of this scope. In the exploitation phase, the component importance measures may be used to allocate inspection and maintenance resources on the most important components. 
Research and achievement of power plant optimal reliability presents complex problem that requires careful and coordinated work in the domain of achieving quality and reliability in electric power system. Important role in solving this problem should be played by methods of forecasting, optimization and normalizing reliability indices with dependence on basic technical and economical parameters, as well as development of methods for achieving reliability in exploitation.

The importance measures quantify the criticality of particular component within a plant design. They have been widely used as tools for identifying components that more significantly influence on the plant behavior with respect to reliability, risk and safety. They can also provide valuable information for the maintenance and operation plant. In this paper, importance measures are used in case when components in thermal power plant exhibit a binary functioning behavior. This implies that plant and its components are either fully functioning or fully failed. For the binary case, components can be ranked with respect to the impact they have on power plant reliability based on a given importance measures. The multi-state reliability analysis can be used in the phase of preparation and design of power plant schemes, but with special attention. Namely, main power plant components (steam boiler, pumps, turbine, generator), because of their characteristics in structural scheme, lose their total capabilities caused by damages. For example, damages in steam boiler pipe system reduce boiler capacity and power output of turbine and generator, but lead to new damages of pipe system and to a bigger loss of steam, finally leading to an outage. It is very important to recognize which parts of main power plant components can be modeled as multi-state components and operate at various levels of performance, opposite to the binary perspective. These types of components may provide functioning or service at degraded component performance levels. In recent years, multi-state system reliability theory and analysis have received considerable attention [7].

The paper is organized as follows: Section 2 provides the overview of component criticality importance measures used in recent literature and applied for thermal power plant design. Section 3 applies and compares importance measures for different options of the structural scheme of conventional thermal power plant, and Section 4 presents conclusions.

\section{REVIEW OF THE MOST WIDELY USED COMPONENT IMPORTANCE MEASURES}

Finding the critical components is an important issue for reliability analysis and the optimization of thermal power plant design. The aim is to obtain information concerning component's contribution to the plant reliability. Reliability importance indices are valuable in establishing direction and prioritization of actions related to reliability improvement in power plant design or in suggesting the most efficient way to operate and maintain plant status. In general, component importance measures in plant use a numerical rank (relative importance), based on certain characteristic of interest, such as the component's contribution to power plant (failure) event occurrence. The most frequently used risk importance metrics are given in [1, 4, 8-12]. The following assumptions are made: (i) independent failure probabilities and repair times for components is common simplification in reliability modeling, (ii) component states and associated probabilities are known, (iii) exponential distribution for repair time and time to failure, (iv) two-state model (in the power plant, components are directly connected to each other) [4].

Birnbaum importance is one of the most widely used importance measures in risk theory. Analytically, Birnbaum measure of importance of component $i$ at time $t$, is defined by:

$$
I_{i}^{B}(t)=\frac{\partial R_{S}(t)}{\partial R_{i}(t)}=R_{S}\left(t ; R_{i}(t)=1\right)-R_{S}\left(t ; R_{i}(t)=0\right)
$$

where $I_{i}^{B}(t)$ is the Birnbaum importance of component $i, R_{\mathrm{S}}(t)$ the system (the power plant in our case) reliability at time $t, R_{i}(t)$ the reliability of component $i$ at time $t, R_{\mathrm{S}}\left(t ; R_{i}(t)=0\right)$ the power plant reliability at time $t$ given component $i$ is failed and $R_{\mathrm{S}}\left(t ; R_{i}(t)=1\right)$ is the power plant reliability at time $t$ given component $i$ is perfectly working.

The Birnbaum importance is basically a sensitivity analysis in plant reliability due to component $i$. If $I_{i}^{B}(t)$ is large, a rather small change in the reliability of component $i$ will have large consequences on the plant reliability at time $t$. The Birnbaum importance ranking represents the maximum loss in plant reliability when component $i$ operates from the condition of perfect functioning $\left(R_{i}(t)=1\right)$ to the condition of certain failure $\left(R_{i}(t)=0\right)$. In (1) Birnbaum's importance measure of component $i$ only depends on the structure of the plant and the reliabilities of the other components. $I_{i}^{B}(t)$ is independent of the reliability $R_{i}(t)$ of component $i$ and this is the weakness of Birnbaum's importance measure. The fact that component $i$ is critical for the system (plant), expresses nothing about the state of component $i$. The definition concerns other components of the 
plant only. If component $i$ is critical for the plant, than component $i$ must either be cut set of order 1 , or be member of cut set where all the other components in the same cut set have failed.

Another popular metric measure, is criticality importance measure that includes the unreliability of component, $F_{i}(t)$, whereas Birnbaum importance measure does not. Analytically, criticality importance is defined as:

$$
I_{i}^{C R}(t)=I_{i}^{B}(t) \frac{F_{i}(t)}{F_{S}(t)}=\left[R_{S}\left(t ; R_{i}(t)=1\right)-R_{S}\left(t ; R_{i}(t)=0\right)\right] \frac{1-R_{i}(t)}{1-R_{S}(t)}
$$

where $F_{i}(t)$ is the unreliability of component $i$ at time $t$ and $F_{\mathrm{S}}(t)$ the system (the power plant) unreliability at time $t$.

Based on this definition, measure of criticality importance $I_{i}^{C R}(t)$ of component $i$ at time $t$ presents the probability that component $i$ is critical for the power plant and is failed at time $t$, when the power plant is failed at time $t$. As motivation for introducing criticality importance measure, we note that component $i$ is critical for the plant, if the other components in the plant are in such states that the plant is functioning, if and only if component $i$ is functioning. To say that component $i$ is critical, the statement about the other components in the plant is needed, and not statement about component $i$. Criticality importance measure is particularly suitable for prioritizing maintenance activities.

The reliability achievement worth (RAW) importance measure of component $i$ is the ratio of the actual power plant reliability obtained when component $i$ is always in perfect functioning $\left(R_{i}(t)=1\right)$ to the actual value of the power plant reliability. The RAW measure determines the maximum percentage increase in the power plant reliability generated by particular component:

$$
I_{i}^{R A W}(t)=\frac{R_{S}\left(t ; R_{i}(t)=1\right)}{R_{S}(t)}
$$

The reliability reduction worth (RRW) importance measure of component $i$ is the ratio of the actual power plant reliability to the value of the plant reliability when component $i$ is always in perfect unreliable $\left(R_{i}(t)=0\right)$. The RRW measure determines the index measuring the potential damage caused to the power plant by a particular component:

$$
I_{i}^{R R W}(t)=\frac{R_{S}(t)}{R_{S}\left(t ; R_{i}(t)=0\right)}
$$

Reliability achievement worth and reliability reduction worth measures are mainly used as a risk importance measures in probabilistic safety assessments of nuclear power plants.

Fussell-Vesely's importance measure $I_{i}^{F V}(t)$ is probability that at least one minimal cut set that contains component $i$ is failed at time $t$, given that the power plant is failed at time $t$. According to this measure, the importance of a component $i$ in the power plant depends on the number and the order of the cutsets where it appears. Analytically, Fussell-Vesely's metric is defined as:

$$
I_{i}^{F V}(t)=\frac{\operatorname{Pr}\left(D_{i}(t)\right)}{\operatorname{Pr}(C(t))} \approx \frac{\sum_{j=1}^{m} \Pi_{j}^{i}(t)}{1-R_{s}(t)}
$$

where $D_{i}(t)$ states that at least one of the minimal cut set containing component $i$ has failed at time $t, C(t)$ states that the power plant is failed at time $t, \Pi_{j}^{i}(t)$ denotes the probability that the minimal cut set $j$, containing component $i$, is failed at time $t$.

Fussell-Vesely's measure takes into consideration the fact that a component may contribute to power plant failure without being critical. The component contributes to plant failure when a minimal cut set, containing the component, is failed. 


\section{COMPONENT IMPORTANCE MEASURES IN THERMAL POWER PLANT DESIGN}

Several options of conventional thermal power plant of $600 \mathrm{MW}$ including main pipes of the first and second loops $\left(\mathrm{I}_{\mathrm{L}}, \mathrm{II}_{\mathrm{L}}\right)$, main circulation pumps and supply (feed) pumps (MCP, SP), steam boilers (SB) and turbines $(\mathrm{T})$ are illustrated in Figure 1. The reliability block diagrams for total failure assessment are presented in Figure 1. Each component has enough capacity to satisfy the needs of its own generator at their nominal power output.
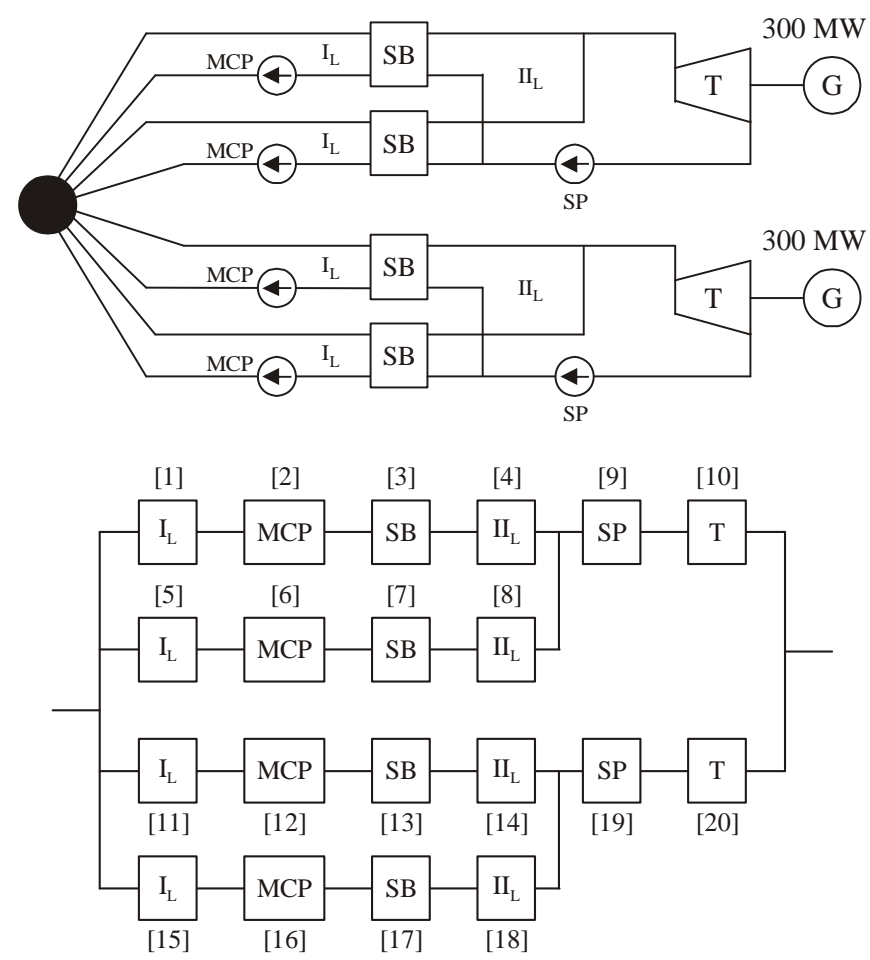

a) Design configuration \#1.
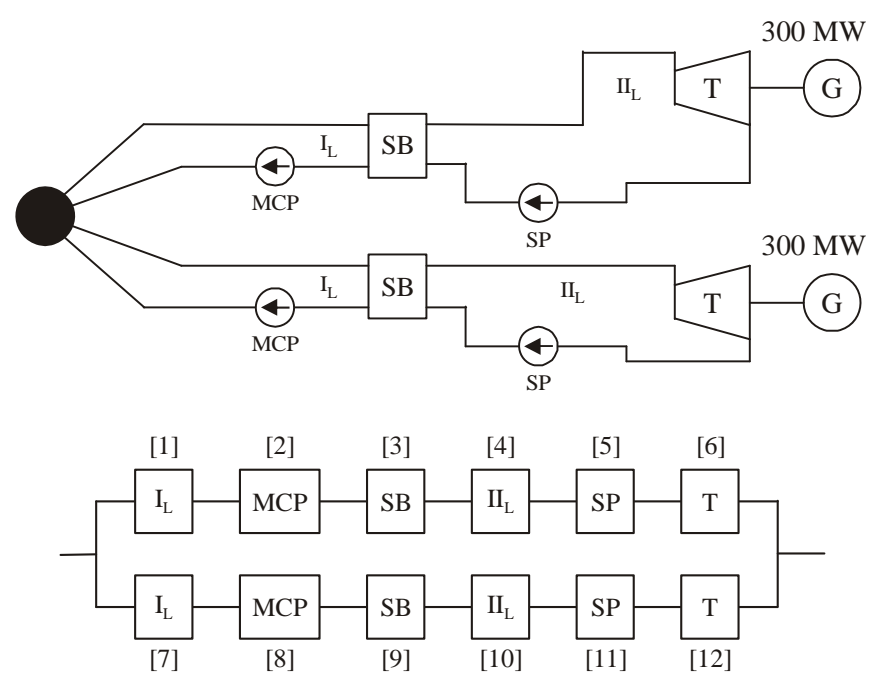

b) Design configuration \#2. 

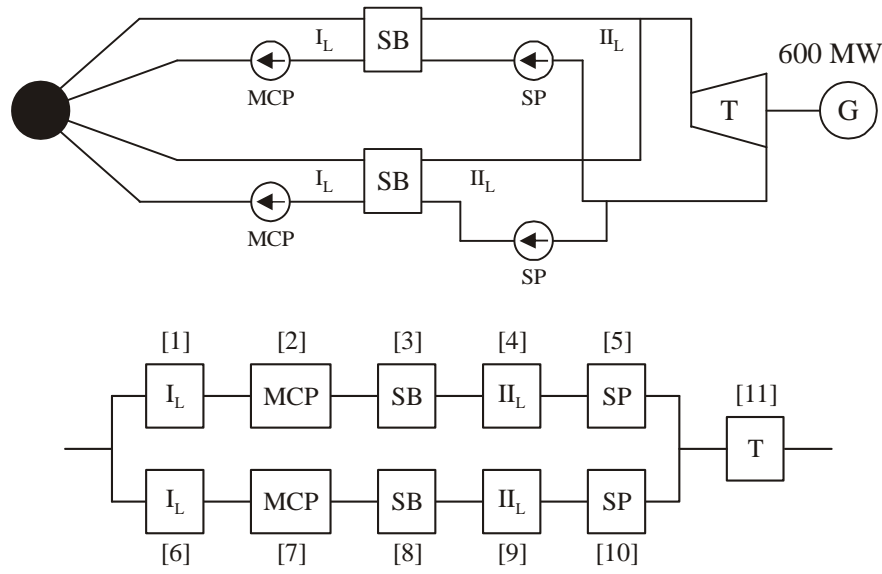

c) Design configuration \#3.

Figure 1. Structural schematic options of conventional thermal power plant of $600 \mathrm{MW}$

Selected design configurations (options) of conventional thermal power plant consider those components, which greatly depend on basic thermodynamic parameters [13, 14]. So, for example, steam boiler is component of synthesized heating surface, air heater, convectional and air economizer, screen and convection steam heaters, etc. Illustrated data applied in the calculation of component criticality importance measures for the thermal power plant design, are presented in Table 1.

Table 1. Component specification and reliability data applied in the calculations

\begin{tabular}{ccccccc}
\hline \multirow{2}{*}{ option } & \multicolumn{6}{c}{ Component reliability } \\
& $\mathrm{I}_{\mathrm{L}}$ & $\mathrm{MCP}$ & $\mathrm{SB}$ & $\mathrm{II}_{\mathrm{L}}$ & $\mathrm{SP}$ & $\mathrm{T}$ \\
\hline$\# 1$ & 0.998 & 0.9945 & 0.997 & 0.998 & 0.9962 & 0.996 \\
$\# 2$ & 0.997 & 0.991 & 0.995 & 0.997 & 0.9962 & 0.996 \\
$\# 3$ & 0.997 & 0.991 & 0.995 & 0.9975 & 0.9962 & 0.992 \\
\hline
\end{tabular}

Reliability importance measures were computed for each component and for each analyzed option. The components were ranked according to their importance based on their respective metric values as given in Tables 2-4. Design configuration are different among themselves in a manner of reliability increase - by complicating structural scheme with great number of components with less capacity (higher quality component). Tables $2-4$ show the metric values and ranking of different components in the analyzed design configurations (options) in case of thermal power plant total failure.

For configuration (option) \#1 the highest ranked component is steam turbine (T), the second ranked component is supply pump (SP), and the least important components are the first and the second loop $\left(\mathrm{I}_{\mathrm{L}}\right.$, $\mathrm{II}_{\mathrm{L}}$ ), as shown in Table 2. This is conceptual identification regarding the component ranking, although each importance metric has respective rank. From all analyzed different metrics, Criticality Importance measure and Fussell-Vesely's measure have closest metric values and equal rank for each component in design option \#1. In this option, minimal cut sets fourth order are dominating because of topological scheme and component capacity that is enough to satisfy needs of owner generator at their nominal output.

For configuration \#2, the highest ranked component is main circulation pump (MCP), the second ranked component is steam boiler (SB), and the least important components are the first and the second loop $\left(\mathrm{I}_{\mathrm{L}}, \mathrm{I}_{\mathrm{L}}\right)$, as shown in Table 2. In this option, all metrics have equal component rankings, except Reliability Reduction Worth importance measure that has rank equal 1 for all components, and does not provide information regarding the most important component. From all analyzed different metrics, Criticality Importance measure and Fussell-Vesely's measure have closest metric values and equal rank for each component in study configuration \#2. In this option, minimal cut sets second order exist because of topological scheme and component capacity that is enough to satisfy needs of owner generator at their nominal output. 
For configuration (option) \#3 the highest ranked component is steam turbine (T), the second ranked component is main circulation pump (MCP), and the least important component is the second loop $\left(\mathrm{II}_{\mathrm{L}}\right)$, as shown in Table 4. In this option, all metrics have equal component rankings, except Reliability Reduction Worth importance measure that has rank equal 2 for all components except steam turbine which has boundless Reliability Reduction Worth value (Inf) and rank equal 1. From all analyzed different metrics, Criticality Importance measure and Fussell-Vesely's measure have closest metric values and equal rank for each component in configuration \#3. In this option minimal cut sets second order exist, plus one minimal cut set first order that relates to turbine outage.

Table 2. Component rankings and metric values for option \#1

\begin{tabular}{ccccccccccccc}
\hline \multirow{2}{*}{ comp. } & \multirow{2}{*}{ mark } & \multicolumn{2}{c}{ Birnbaum } & \multicolumn{2}{c}{ Criticality } & \multicolumn{2}{c}{ Fussell-Vesely } & \multicolumn{2}{c}{ RAW } \\
& & rank & value & rank & value & rank & value & rank & value & rank & value \\
\hline $\mathrm{I}_{\mathrm{L}}$ & $1,5,11,15$ & 3 & 0.000097 & 5 & 0.003079 & 5 & 0.003156 & 4 & 1.000000 & 2 & 1.000097 \\
$\mathrm{MCP}$ & $2,6,12,16$ & 3 & 0.000097 & 3 & 0.008496 & 3 & 0.008680 & 3 & 1.000001 & 2 & 1.000097 \\
$\mathrm{SB}$ & $3,7,13,17$ & 3 & 0.000097 & 4 & 0.004622 & 4 & 0.004734 & 4 & 1.000000 & 2 & 1.000097 \\
$\mathrm{II}$ & $4,8,14,18$ & 3 & 0.000097 & 5 & 0.003079 & 5 & 0.003156 & 4 & 1.000000 & 2 & 1.000097 \\
$\mathrm{SP}$ & 9,19 & 2 & 0.007906 & 2 & 0.476692 & 2 & 0.479752 & 2 & 1.000030 & 1 & 1.007938 \\
$\mathrm{~T}$ & 10,20 & 1 & 0.007907 & 1 & 0.501882 & 1 & 0.505002 & 1 & 1.000032 & 1 & 1.007938 \\
\hline
\end{tabular}

$\begin{array}{ll}\text { minimal cut sets: } & \{1,5,11,15\},\{1,5,11,16\},\{1,5,11,17\},\{1,5,11,18\},\{1,5,12,15\},\{1,5,12,16\},\{1,5,12,17\},\{1,5,12,18\}, \\ & \{1,5,13,15\},\{1,5,13,16\},\{1,5,13,17\},\{1,5,13,18\},\{1,5,14,15\},\{1,5,14,16\},\{1,5,14,17\},\{1,5,14,18\},\end{array}$ $\{1,5,19\},\{1,5,20\}$,

$\{1,6,11,15\},\{1,6,11,16\},\{1,6,11,17\},\{1,6,11,18\},\{1,6,12,15\},\{1,6,12,16\},\{1,6,12,17\},\{1,6,12,18\},\{1,6,13,15\},\{1,6,13,16\}$, $\{1,6,13,17\},\{1,6,13,18\},\{1,6,14,15\},\{1,6,14,16\},\{1,6,14,17\},\{1,6,14,18\},\{1,6,19\},\{1,6,20\}$,

$\{1,7,11,15\},\{1,7,11,16\},\{1,7,11,17\},\{1,7,11,18\},\{1,7,12,15\},\{1,7,12,16\},\{1,7,12,17\},\{1,7,12,18\},\{1,7,13,15\},\{1,7,13,16\}$, $\{1,7,13,17\},\{1,7,13,18\},\{1,7,14,15\},\{1,7,14,16\},\{1,7,14,17\},\{1,7,14,18\},\{1,7,19\},\{1,7,20\}$,

$\{1,8,11,15\},\{1,8,11,16\},\{1,8,11,17\},\{1,8,11,18\},\{1,8,12,15\},\{1,8,12,16\},\{1,8,12,17\},\{1,8,12,18\},\{1,8,13,15\},\{1,8,13,16\}$, $\{1,8,13,17\},\{1,8,13,18\},\{1,8,14,15\},\{1,8,14,16\},\{1,8,14,17\},\{1,8,14,18\},\{1,8,19\},\{1,8,20\}$,

$\{2,5,11,15\},\{2,5,11,16\},\{2,5,11,17\},\{2,5,11,18\},\{2,5,12,15\},\{2,5,12,16\},\{2,5,12,17\},\{2,5,12,18\},\{2,5,13,15\},\{2,5,13,16\}$, $\{2,5,13,17\},\{2,5,13,18\},\{2,5,14,15\},\{2,5,14,16\},\{2,5,14,17\},\{2,5,14,18\},\{2,5,19\},\{2,5,20\}$,

$\{2,6,11,15\},\{2,6,11,16\},\{2,6,11,17\},\{2,6,11,18\},\{2,6,12,15\},\{2,6,12,16\},\{2,6,12,17\},\{2,6,12,18\},\{2,6,13,15\},\{2,6,13,16\}$, $\{2,6,13,17\},\{2,6,13,18\},\{2,6,14,15\},\{2,6,14,16\},\{2,6,14,17\},\{2,6,14,18\},\{2,6,19\},\{2,6,20\}$,

$\{2,7,11,15\},\{2,7,11,16\},\{2,7,11,17\},\{2,7,11,18\},\{2,7,12,15\},\{2,7,12,16\},\{2,7,12,17\},\{2,7,12,18\},\{2,7,13,15\},\{2,7,13,16\}$ $\{2,7,13,17\},\{2,7,13,18\},\{2,7,14,15\},\{2,7,14,16\},\{2,7,14,17\},\{2,7,14,18\},\{2,7,19\},\{2,7,20\}$,

$\{2,8,11,15\},\{2,8,11,16\},\{2,8,11,17\},\{2,8,11,18\},\{2,8,12,15\},\{2,8,12,16\},\{2,8,12,17\},\{2,8,12,18\},\{2,8,13,15\},\{2,8,13,16\}$, $\{2,8,13,17\},\{2,8,13,18\},\{2,8,14,15\},\{2,8,14,16\},\{2,8,14,17\},\{2,8,14,18\},\{2,8,19\},\{2,8,20\}$,

$\{3,5,11,15\},\{3,5,11,16\},\{3,5,11,17\},\{3,5,11,18\},\{3,5,12,15\},\{3,5,12,16\},\{3,5,12,17\},\{3,5,12,18\},\{3,5,13,15\},\{3,5,13,16\}$, $\{3,5,13,17\},\{3,5,13,18\},\{3,5,14,15\},\{3,5,14,16\},\{3,5,14,17\},\{3,5,14,18\},\{3,5,19\},\{3,5,20\}$,

$\{3,6,11,15\},\{3,6,11,16\},\{3,6,11,17\},\{3,6,11,18\},\{3,6,12,15\},\{3,6,12,16\},\{3,6,12,17\},\{3,6,12,18\},\{3,6,13,15\},\{3,6,13,16\}$, $\{3,6,13,17\},\{3,6,13,18\},\{3,6,14,15\},\{3,6,14,16\},\{3,6,14,17\},\{3,6,14,18\},\{3,6,19\},\{3,6,20\}$,

$\{3,7,11,15\},\{3,7,11,16\},\{3,7,11,17\},\{3,7,11,18\},\{3,7,12,15\},\{3,7,12,16\},\{3,7,12,17\},\{3,7,12,18\},\{3,7,13,15\},\{3,7,13,16\}$, $\{3,7,13,17\},\{3,7,13,18\},\{3,7,14,15\},\{3,7,14,16\},\{3,7,14,17\},\{3,7,14,18\},\{3,7,19\},\{3,7,20\}$,

$\{3,8,11,15\},\{3,8,11,16\},\{3,8,11,17\},\{3,8,11,18\},\{3,8,12,15\},\{3,8,12,16\},\{3,8,12,17\},\{3,8,12,18\},\{3,8,13,15\},\{3,8,13,16\}$, $\{3,8,13,17\},\{3,8,13,18\},\{3,8,14,15\},\{3,8,14,16\},\{3,8,14,17\},\{3,8,14,18\},\{3,8,19\},\{3,8,20\}$,

$\{4,5,11,15\},\{4,5,11,16\},\{4,5,11,17\},\{4,5,11,18\},\{4,5,12,15\},\{4,5,12,16\},\{4,5,12,17\},\{4,5,12,18\},\{4,5,13,15\},\{4,5,13,16\}$, $\{4,5,13,17\},\{4,5,13,18\},\{4,5,14,15\},\{4,5,14,16\},\{4,5,14,17\},\{4,5,14,18\},\{4,5,19\},\{4,5,20\}$,

$\{4,6,11,15\},\{4,6,11,16\},\{4,6,11,17\},\{4,6,11,18\},\{4,6,12,15\},\{4,6,12,16\},\{4,6,12,17\},\{4,6,12,18\},\{4,6,13,15\},\{4,6,13,16\}$, $\{4,6,13,17\},\{4,6,13,18\},\{4,6,14,15\},\{4,6,14,16\},\{4,6,14,17\},\{4,6,14,18\},\{4,6,19\},\{4,6,20\}$,

$\{4,7,11,15\},\{4,7,11,16\},\{4,7,11,17\},\{4,7,11,18\},\{4,7,12,15\},\{4,7,12,16\},\{4,7,12,17\},\{4,7,12,18\},\{4,7,13,15\},\{4,7,13,16\}$, $\{4,7,13,17\},\{4,7,13,18\},\{4,7,14,15\},\{4,7,14,16\},\{4,7,14,17\},\{4,7,14,18\},\{4,7,19\},\{4,7,20\}$,

$\{4,8,11,15\},\{4,8,11,16\},\{4,8,11,17\},\{4,8,11,18\},\{4,8,12,15\},\{4,8,12,16\},\{4,8,12,17\},\{4,8,12,18\},\{4,8,13,15\},\{4,8,13,16\}$, $\{4,8,13,17\},\{4,8,13,18\},\{4,8,14,15\},\{4,8,14,16\},\{4,8,14,17\},\{4,8,14,18\},\{4,8,19\},\{4,8,20\}$,

$\{9,11,15\},\{9,11,16\},\{9,11,17\},\{9,11,18\},\{9,12,15\},\{9,12,16\},\{9,12,17\},\{9,12,18\},\{9,13,15\},\{9,13,16\},\{9,13,17\},\{9,13,18\}$, $\{9,14,15\},\{9,14,16\},\{9,14,17\},\{9,14,18\},\{9,19\},\{9,20\}$,

$\{10,11,15\},\{10,11,16\},\{10,11,17\},\{10,11,18\},\{10,12,15\},\{10,12,16\},\{10,12,17\},\{10,12,18\},\{10,13,15\},\{10,13,16\},\{10,13,17\}$, $\{10,13,18\},\{10,14,15\},\{10,14,16\},\{10,14,17\},\{10,14,18\},\{10,19\},\{10,20\}$ 
Table 3. Component rankings and metric values for option \#2

\begin{tabular}{|c|c|c|c|c|c|c|c|c|c|c|c|}
\hline \multirow{2}{*}{ comp. } & \multirow{2}{*}{ mark } & \multicolumn{2}{|c|}{ Birnbaum } & \multicolumn{2}{|c|}{ Criticality } & \multicolumn{2}{|c|}{ Fussell-Vesely } & \multicolumn{2}{|c|}{ RAW } & \multicolumn{2}{|c|}{ RRW } \\
\hline & & rank & value & rank & value & rank & value & rank & value & rank & value \\
\hline $\mathrm{I}_{\mathrm{L}}$ & 1,7 & 5 & 0.026817 & 5 & 0.106440 & 5 & 0.110341 & 5 & 1.000081 & 1 & 1.027493 \\
\hline МСР & 2,8 & 1 & 0.026980 & 1 & 0.321252 & 1 & 0.331022 & 1 & 1.000243 & 1 & 1.027493 \\
\hline SB & 3,9 & 2 & 0.026871 & 2 & 0.177756 & 2 & 0.183901 & 2 & 1.000134 & 1 & 1.027493 \\
\hline $\mathrm{II}_{\mathrm{L}}$ & 4,10 & 5 & 0.026817 & 5 & 0.106440 & 5 & 0.110341 & 5 & 1.000081 & 1 & 1.027493 \\
\hline SP & 5,11 & 4 & 0.026839 & 4 & 0.134932 & 4 & 0.139765 & 4 & 1.000102 & 1 & 1.027493 \\
\hline $\mathrm{T}$ & 6,12 & 3 & 0.026844 & 3 & 0.142062 & 3 & 0.147121 & 3 & 1.000107 & 1 & 1.027493 \\
\hline minim & ets: & $\begin{array}{l}\{1,7\}, \\
\{3,7\}, \\
\{5,7\},\end{array}$ & $\begin{array}{l}\},\{1,9\},\{ \\
\},\{3,9\}, \\
\},\{5,9\},\{\end{array}$ & $\begin{array}{r}\},\{ \\
\},\{ \\
\},\{\end{array}$ & $\begin{array}{l}\},\{1,12\}, \\
\},\{3,12\}, \\
\},\{5,12\},\end{array}$ & \} & $\begin{array}{l},\{2,9\},\{2 \\
,\{4,9\},\{4 \\
,\{6,9\},\{6\end{array}$ & $\begin{array}{l}\{2 \\
\{4 \\
\{6\end{array}$ & $\begin{array}{l}\{2,12\}, \\
\{4,12\}, \\
\{6,12\}\end{array}$ & & \\
\hline
\end{tabular}

Table 4. Component rankings and metric values for option \#3

\begin{tabular}{|c|c|c|c|c|c|c|c|c|c|c|c|}
\hline \multirow{2}{*}{ comp. } & \multirow{2}{*}{ mark } & \multicolumn{2}{|c|}{ Birnbaum } & \multicolumn{2}{|c|}{ Criticality } & \multicolumn{2}{|c|}{ Fussell-Vesely } & \multicolumn{2}{|c|}{ RAW } & \multicolumn{2}{|c|}{ RRW } \\
\hline & & rank & value & rank & value & rank & value & rank & value & rank & value \\
\hline $\mathrm{I}_{\mathrm{L}}$ & 1,6 & 5 & 0.022451 & 5 & 0.007897 & 5 & 0.008195 & 5 & 1.000068 & 2 & 1.023097 \\
\hline MCP & 2,7 & 2 & 0.022587 & 2 & 0.023833 & 2 & 0.024586 & 2 & 1.000205 & 2 & 1.023097 \\
\hline SB & 3,8 & 3 & 0.022496 & 3 & 0.013187 & 3 & 0.013659 & 3 & 1.000113 & 2 & 1.023097 \\
\hline $\mathrm{II}_{\mathrm{L}}$ & 4,9 & 6 & 0.022439 & 6 & 0.006577 & 6 & 0.006829 & 6 & 1.000057 & 2 & 1.023097 \\
\hline SP & 5,10 & 4 & 0.022469 & 4 & 0.010010 & 4 & 0.010381 & 4 & 1.000086 & 2 & 1.023097 \\
\hline $\mathrm{T}$ & 11 & 1 & 0.999467 & 1 & 0.937452 & 1 & 0.937953 & 1 & 1.008065 & 1 & Inf \\
\hline minim & & $\begin{array}{l}\{1,6\}, \\
\{4,7\},\end{array}$ & $\begin{array}{l}\{1,8\}, \\
\{4,9\},\end{array}$ & 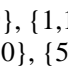 & $\begin{array}{l}\{2,6\},\{2 \\
\{5,7\},\{5\end{array}$ & 2, & $\begin{array}{l}, 9\},\{2,1 \\
, 10\},\{11\end{array}$ & 6 & $7\},\{3,8\}$ & & $\{4,6\}$ \\
\hline
\end{tabular}

The observations from the experimental results in the different design configurations (options) for total failure of thermal power plant include:

1. The Reliability Reduction Worth importance measure cannot distinguish between components that occupy appropriate position in a series structure but have significantly different failure probabilities. This result is not rational because it is clear that the most unreliable component in the series structure should be the highest ranked at the rank list.

2. Among the analyzed metrics, Criticality Importance measure and Fussell-Vesely's measure are the most dynamic and responsive. The components that occupy similar structural positions, but have different reliabilities, will be ranked differently. Generally, these metrics induce reasonable conclusions and these can be used to select the candidate components for improvement.

3. Birnbaum metric, as well as Reliability Achievement Worth for option \#1, cannot recognize the ranking of components in parallel structure with significant different reliabilities. This may lead to mislead ordering in terms of guiding the system maintenance.

4. When Birnbaum metric is high and the basic components unavailability already fairly low, one could think of introducing extra redundancy.

\section{CONCLUSIONS}

The analysis of the thermal power plants reliability is usually based on simple indexes that do not take into account the criticality of some failures. This criticality should be evaluated on reliability concepts that consider the effect of a component failure on the power plant performance. Although reliability importance measure have been developed for the power industry and applied in transmission and distribution systems, it can be useful metrics to rank components regarding their impact on power plant reliability, operation and maintenance. These analyzed measures serve as very useful tools for reliability improvement components and as very valuable information for decision-makers to evaluate where investments could be made in order to improve the functioning and reliability of the power plant.

In this paper structural schematic options of conventional thermal power plant of $600 \mathrm{MW}$ show that the used importance measures can be used as an effective tool to assess component criticality in the phase of preparation and design of new production capacities. 


\section{REFERENCES}

[1] M. van der Borst, and H. Schoonakker, "An overview of PSA importance measures", Reliability Engineering and System Safety, ELSEVIER, vol. 72, pp. 241-245, 2001.

[2] L. Lu, and J. Jiang, "Probabilistic safety assessment for instrumentation and control systems in nuclear power plants: An overview", Journal of Nuclear Science and Technology, vol. 41, no. 3, pp. 323-330, 2004.

[3] W. Wendai, et al, "Reliability importance of components in a complex system", in: IEEE Proceedings of Annual Reliability and Maintainability Symposium, Los Angeles California, 2004.

[4] J.F. Espiritu, et al, "Component criticality importance measures for the power industry", Electric Power Systems Research, ELSEVIER vol. 77, pp. 407-420, 2007.

[5] G. Hamoud, et al, "Assessment of component criticality in customer delivery systems", in: Proceedings of the Eighth International Conference on Probabilistic Methods Applied to Power Systems, Iowa State University, Ames, Iowa, 2004.

[6] P. Hilber, and L. Bertling, "Monetary importance of component reliability in electrical networks for maintenance optimization", in: Proceedings of the Eighth International Conference on Probabilistic Methods Applied to Power Systems, Iowa State University, Ames, Iowa, 2004.

[7] J.E. Ramirez-Marquez, and D. Coit, "Composite importance measures for multi-state systems with multi-state components", IEEE Transactions on Reliability, vol. 54, no. 3, pp. 517-529, 2005.

[8] J.E. Ramirez-Marquez, et al, "New insights on multi-state component criticality and importance", Reliability Engineering and System Safety, ELSEVIER, vol. 91, pp. 894-904, 2005.

[9] W. Wang, J. Loman, and P. Vassiliou, "Reliability importance of components in a complex system", IEEE Proceedings of Annual Reliability and Maintainability Symposium, Los Angeles, California, USA, 2004.

[10] M. Rausand, and A. Hoyland, System reliability theory - models, statistical methods and applications, 2nd edition, John Wiley \& Sons, New York, Inc, 2004.

[11] A. Gandini, "Importance and sensitivity analysis in assessing system reliability", IEEE Transactions on Reliability, vol. 39, no. 1, pp. 61-70, 1990.

[12] G. Levitin, et al, "Generalized importance measures for multistate elements based on performance level restrictions", Reliability Engineering and System Safety, ELSEVIER vol. 82, pp. 63-73, 2003.

[13] G.F.M. de Souza, Thermal power plant performance analysis, Springer, London, 2012.

[14] S. Bisanovic, and H. Sehovic, "Optimal reliability of power capacities in the phase of preparation and design", International Journal of Reliability and Safety, Inderscience Publishers, vol. 2, no. 4, pp. 340-356, 2008.

\section{BIOGRAPHIES OF AUTHORS}

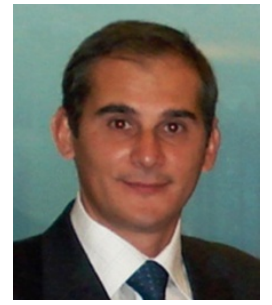

Smajo Bisanovic received the degree of Electrical Engineer in 1991, MSc degree in 1994 and PhD degree in 2009 from the Faculty of Electrical Engineering, University of Sarajevo, Bosnia and Herzegovina. He is associate professor at the Faculty of Electrical Engineering, University of Sarajevo, Bosnia and Herzegovina. His areas of interest include operation, planning and economics of power systems and application of reliability theory to power systems.

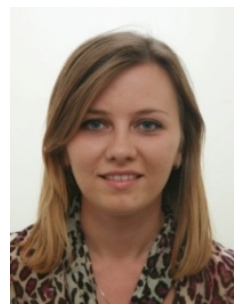

Mersiha Samardzic received a BSc degree in power electrical engineering for the Faculty of Electrical Engineering, University of Sarajevo, Bosnia and Herzegovina in 2014. She is now pursuing her MSc degree in the same Faculty. Her research interests include computer simulations and design analysis applied to power systems.

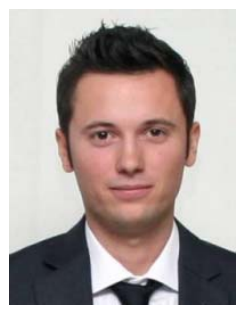

Damir Aganovic is received a MSc degree in power electrical engineering from the Faculty of Electrical Engineering, University of Sarajevo, Bosnia and Herzegovina in 2010. He is currently pursuing his $\mathrm{PhD}$ degree in the same field at the same University. He is an Expert associate for Power System Operation Management at Public Enterprise Elektroprivreda of Bosnia and Herzegovina. His areas of interest include operation and planning of power systems. 